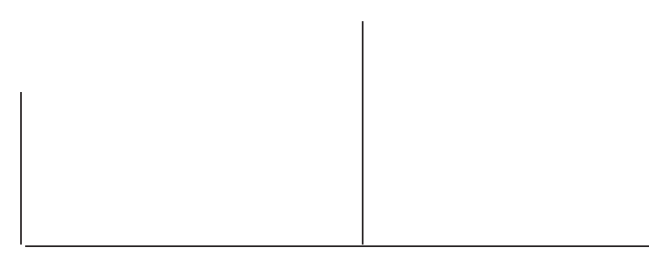

Rev. Latinoam. Psicopat. Fund., IV, 3, 38-46

\title{
Las identificaciones en los procesos psicóticos supersticiosos infantiles, una negociación con los espíritus
}

\author{
Rebeca Oñate Galván \\ Alejandra Plaza Espinosa \\ José de Jesús González Núñez
}

\footnotetext{
El niño psicótico supersticioso lucha contra sus identificaciones consistentes, y las supersticiones se vuelven defensas no exitosas y disfraces de identificaciones por el riesgo de muerte psíquica ante las regresiones psicóticas simbióticas. Lupita, de 10 años de edad, asegura que a veces es poseída por los malos espíritus; ya que como un cuerpo sin alma toma la voz de otro para sobrevivir y así, a través de sus supersticiones intenta en vano tener una alma propia.
}

Palabras llave: Psicoanálisis, procesos psicóticos, identificaciones 
El niño proyecta en las creencias supersticiosas su temor a ser devorado por el objeto amado, es decir, se defiende fervientemente contra la angustia ante la simbiosis psicótica; pero al mismo tiempo esas creencias supersticiosas lo ayudan a lidiar con este conflicto, ya que al contar con la compañía de las ánimas, espíritus malignos, fantasmas, dioses y demonios, hace un trato con sus objetos de los cuales no está permitido diferenciarse, ni separarse (Fenichel, 1986). El niño psicótico supersticioso intercambia vivir con los espíritus aunque lo atemoricen, a cambio de que no exista una ruptura total con la realidad, y aunque exista un manejo deficiente de ésta, puede continuar realizando actividades cotidianas de la vida de un niño, como lo es por ejemplo acudir a la escuela a estudiar.

Lupita es una niña de 10 años de edad. Llegó a tratamiento a los 5 años cuando en el kinder comenzó a tener problemas para socializar, y las maestras relataban como se quedaba paralizada a la hora del recreo sin poder jugar con ningún niño, sin embargo su rendimiento escolar era satisfactorio. Físicamente parece mayor porque es más alta que las niñas de su edad, y además es obesa como su madre. La obesidad es un símbolo de la unión simbiótica de Lupita con su madre (Pankow, 1979). Lupita es miembro de una familia psicótica simbiótica, de clase social baja, que está conformada por la abuela materna, figura matriarcal que asumió el maternaje de Lupita y con la que estaba simbiótizada al llegar a tratamiento. El padre, hombre impulsivo, agresivo, y dependiente, es una figura rechazada, pero a la vez deseada eróticamente en la familia. La madre, mujer obesa, padece frecuentes ataques paranoicos que la paralizan hasta 


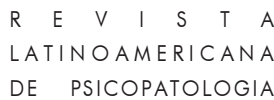

el grado de pasar prolongados períodos sin poder salir de casa (semanas, incluso meses). Y por último un hermano menor que es el orgullo del padre por ser hombre $\mathrm{y}$ al que sobreprotegen todos.

Esta familia tiene profundas y arraigadas costumbres religiosas antiguas siendo la que predomina el culto a los muertos, de hecho Lupita llega a tratamiento a los días siguientes de haber pasado las festividades mexicanas del día de muertos, que esta familia festeja durante una semana completa en el pueblo de Mixquic (pueblo donde tradicionalmente cada año, el dos de noviembre, se celebra el día de muertos con más fervor). La familia cree en las ánimas (almas en pena), en los espíritus malignos, temen al demonio y a las posesiones demoniacas.

Estas creencias tienen su origen en la etapa más temprana de la relación primera madre-hijo, en donde la abuela-madre es una maga, es una diosa todopoderosa, que puede realizar cualquier acción con tan sólo desearlo, y el niño en la relación simbiótica con ella comparte estos poderes también deseándolos (Roheim, 1982; Fenichel, 1986). Para Lupita la creencias supersticiosas cumplen dos funciones: 1) compartir la omnipotencia de su abuela-maga y de esta forma en lo simbólico permanecer simbiotizada con ella, siendo esto un fingimiento identificatorio porque equivale a ser la abuela misma, y además significa que la puede acompañar a donde quiera que vaya o aparecer cuando la necesite; 2) defenderse contra la omnipotencia de la abuela, ya que las identificaciones con las ánimas la dotan de poderes equivalentes a los de la abuela-madre-maga.

Los disfraces identificatorios son producto de vínculos débiles, enfermizos, inexistentes o igualmente fingidos y, como si fueran una maldición de dioses crueles debilitan y envenenan aún más esos vínculos desquebrajados. Así, en la relación madre-padre-hijo, los padres del niño psicótico supersticioso no cumplen su función metabolizadora, y de firme contacto con la realidad, lo que provoca una internalización de objetos confusos, angustiantes y aterradores que se asemajan a los impulsos no neutralizados del propio niño. Por lo tanto, lo interno es malo y para poder sobrevivir hay que expulsarlo, ya afuera hay que atacar a esos demonios y malos espíritus para exterminarlos antes de que ellos terminen con el niño, matándolo al poseerlo en cuerpo y alma. Pero como luego, hay que introyectar nuevamente para no quedar vacío, para no quedar sólo y desprotegido, separado del objeto simbiótico omnipotente, entonces, los espíritus malignos regresan al niño para acompañarlo, y lo salvan momentáneamente para enfrentar las situaciones de la realidad que se le dificultan, pero no lo salvan de la maldición de seguir temiéndoles y de no poseer un alma propia.

Así es como Lupita llega a tratamiento, catatónica, llena de terror a ser poseída por los espíritus. Probablemente en la transferencia, siente temor a ser poseída por la analista, una persona desconocida que podría ser un ánima disfrazada de analista. 


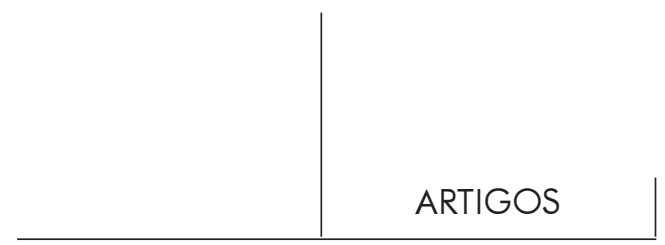

A Lupita sólo la contenía el saber que a pocos metros estaban todos sus familiares (abuela, madre, padre y hermano), pero si al salir del consultorio, no los veía irrumpía en llanto y se paralizaba expresando miedo a que se la robaran. Ahora se entiende que era miedo a enfrentarse a la situación real por si misma, a quedarse sola y que le robaran su alma fingida.

Poco a poco, Lupita adquirió confianza con muchas reservas, pero la suficiente al fin, que le permitiera estar con la analista en el consultorio. El primer año de tratamiento Lupita observó a la terapeuta jugar a la mamá, a construir casas, y a dibujar personas, hasta que ella logró imitar el juego. De esta manera, llegó un día que Lupita rompió el silencio y le preguntó a la analista si creía en Dios, en el diablo y en las ánimas porque su abuela le había dicho que estaban por todas partes. En ese momento Lupita se paralizó y sus ojos se movieron rápidamente de un lado a otro como cuando se sueña y su cara expresaba miedo. Lupita tuvo confianza con la analista para hablar de su conflicto de identidad, y se atemorizó de ser castigada por acercarse a otra persona que no fuera la abuela-madre. En ese momento se le “aparece" un ánima. El niño psicótico supersticioso teme la relación afectiva, y rechaza reconocer el cariño y la relación intensa con las personas porque no sabe controlar la actividad normal de sus propios impulsos, por lo que rechaza la identificación verdadera y sólo imita a los que lo rodean (Freud, A. 1989). Sólo sabe relacionarse con y en compañía de su compañero simbiótico. De esta manera, Lupita invocó a las ánimas, o sea a la abuela, aunque con temor a sus represalias, pero con la intención de calmarla y que la acompañara en la sesión, de esa forma se reaseguró y pudo continuar hablando con la analista.

A lo largo del tratamiento, en las sesiones, Lupita se disfrazaba de su abuela, de su madre, y de su padre. Como si fueran almas que se metían en su cuerpo para cobrar vida y que la acompañaban y ayudaban a enfrentar todas las situaciones difíciles en las sesiones. Anna Freud (1989) comenta que los niños psicóticos utilizan identificaciones del tipo más arcaico, en la época anterior a que exista algún objeto amoroso. De tal manera que sus constantes cambios en las identificaciones significan un empobrecimiento del yo, ya que no logran la constancia con un objeto con el cual se identifiquen por acción de vínculos libidinales estables que fortalezcan el yo en un manejo claro de la realidad y que por lo tanto, existan las oportunidades para las identificaciones con un superyo más benévolo.

Además el niño psicótico supersticioso se disfraza porque sus padres no lo nutren psíquicamente con su propia mente, por el contrario los padres invaden la mente del niño con sus propios espíritus malignos (impulsos no neutralizados), y el niño tiene sólo la opción de morir psíquicamente o de fingir existir para no ser aniquilado o poseído completamente en la refusión simbiótica (Sperling, 1980; Mahler, 1990). Poco a poco en las sesiones comenzó a predominar el tema supersticioso 


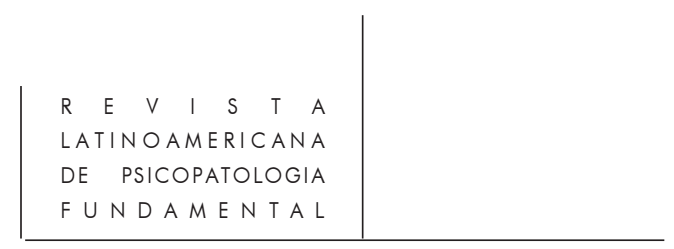

religioso y Lupita comentaba que siempre cuando pensaba en Dios, se le venía a la mente el diablo, le daba mucho miedo y luego pensaba en la muerte. La muerte simboliza a su madre que la confundía y la aniquilaba con sus miedos mortíferos; mientras que el diablo representa al padre una figura grotesca con su sexualidad incestuosa, que puede separar a Lupita de la abuela-madre; y por lo tanto es una figura amenazante y psicotizante. Así, ambos padres sumidos en una guerra encarnizada uno contra el otro, ponen en un dilema a Lupita quien no puede identificarse con ninguno porque uno significa la muerte psíquica y el otro la locura, ambos sinónimos e igual de aterradores.

El momento edípico, entre el tercer y cuarto año de edad detona en el niño psicótico simbiótico, reacciones agudas de pánico que se manifiestan en estados catatónicos debido a las complejas demandas emocionales de la situación edípica que impulsan al niño hacia la amenaza de la diferenciación (Reca, 1979). El concepto de si mismo está constituido por componentes emocionales adversos que lo amenazan con sentimientos avasalladores que se refieren a ser inferior, inadecuado, indigno de ser amado, e incapaz de encontrar por si mismo el camino en el manejo de la realidad. Un día, en una de las sesiones, Lupita le confiesa a la analista dos eventos que ella cataloga de pecados, lo que la hace sentirse inadecuada e indigna de ser amada. Primero le comenta que en la noche cuando todos están dormidos ella continúa despierta y le da mucho miedo pararse para ir al baño porque tiene que pasar por la habitación de los padres y le atemorizan los ruidos feos que escucha provenientes de esa habitación. Consecuentemente ante el temor de los ruidos piensa en las ánimas y luego se pone a rezar con más fervor. En la casa de Lupita no hay puertas que resguarden la intimidad de las habitaciones, y la situación edípica y la escena primaria representan la confusión de la diferenciación psicosexual ya que, al igual que su casacuerpo no tiene límites-puertas que resguarden su identidad. Recurre a Dios para que con su omnipotencia pueda conservar su bisexualidad infantil (Freud, 1905) y supere la menaza de la diferenciación además de lograr un acto de realidad como es pararse e ir al baño y no orinarse en la cama.

Luego comenta que el segundo pecado es que un brujo fue a su casa para hacer una limpia, para sacar a los espíritus malignos, que a su decir, se apoderan de ellos. Lupita platica las sensaciones de su madre con el exorcismo y ella al igual que su madre ve nubes grises que representan la imagen bizarra del pecho materno al inicio del establecimiento de la simbiosis. Así, el niño psicótico supersticioso utiliza esas identificaciones bizarras con las ánimas, demonios y dioses en los momentos regresivos por la angustia ante la cercanía afectiva con las personas con las que comienza a relacionarse con mayor intensidad, y es cuando teme ser reengolfado, se regresiona y en sus supersticiones se protege y proyecta su mundo caótico. Esa es su única manera de lidiar con ese objeto internalizado y además seguir relacionándose 


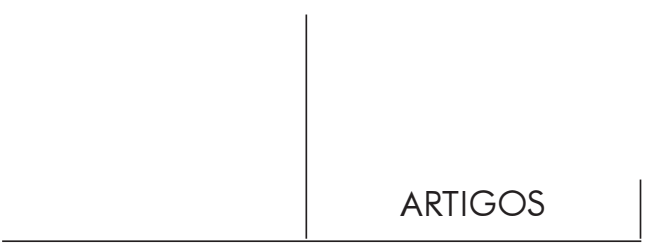

con el objeto de la realidad, al contar con la protección del contexto supersticioso que es omnipotente. Esta distancia supersticiosa, el niño la utiliza para preservar su yo de la sensación de desintegración. Sin embargo, algunas defensas neuróticas siguen impidiendo una total regresión y la pérdida de todo el contacto con la realidad.

En el tercer año de tratamiento, la relación transferencial con la analista se fue haciendo más fuerte y Lupita comenzó a expresar abiertamente su oposición a identificarse con alguien de su familia y a desplazar la relación a sus mascotas con quienes constataba que ella podía cuidar y dar protección. Fue la primera vez que se le escuchó entusiasmada y encariñada. Actualmente, con sus perros se siente segura, sin miedo y contenta. Durante meses el tratamiento giró alrededor del cuidado de sus perros, desplazando en estos sus primeras manifestaciones de afecto y cuidado que fue introyectándose después de tres años e medio de tratamiento psicoanalítico.

Sin embargo, la relación transferencial es negada por el miedo a la simbiosis psicótica, además de que a la transferencia se le atribuyen poderes mágicos y malignos. Esto se puede ver clínicamente en la costumbre de Lupita de llevar a la analista cada día de muertos una calavera (dulce típico del día de muertos hecho de azúcar o chocolate). Con el paso del tiempo en el tratamiento, la transferencia negada se revela con más intensidad en el cuarto año, cuando Lupita, regala a la analista una enorme calavera de azúcar blanca $(30 \mathrm{cms}$ de alto) con cabello güero, que la representaba y que causó contratransferencialmente un intenso y desagradable escalofrío por la connotación simbólica de la identificación de la terapeuta con la muerte. Lupita lleva una ofrenda a la muerte para apaciguar la ira de la abuela-madre y su propio temor a establecer ahora en la transferencia una relación simbiótica con la analista, quien se puede comer la calavera de azúcar; es decir, se puede comer a la muerte, Lupita le transfiere a la analista los poderes de la abuela-madre, pero la analista como objeto transferencial si le permite tener una identidad propia.

Poco a poco, Lupita comenzó hablar de Dios, a integrar una parte protectora y buena en si misma, relató que Dios le decía "Lupita no te asustes yo te estoy cuidando, y siempre te voy a cuidar". Pero se asusta de nuevo de traicionar a su abuela-madre y aparece el fantasma de la abuela para acompañarla de nuevo y seguir trabajando con la analista. Después de varias sesiones llega y dice que ya lo pensó mejor, que más bien ella tiene dos almas una buena cuando está contenta y otra mala cuando se enoja, y que se enoja cuando su mamá quiere que sea como ella, y dice con mucha desesperación "quiero hacerlos entender que no hay dos iguales que ellos, yo soy yo, y ellos ellos". El niño que desarrolla este tipo de trastorno, frecuentemente teme que la gente pueda leer sus pensamientos y descubra la hostilidad que siente hacia sus padres y que lo castiguen por sus malos pensamientos (González Núñez, 1992). La menor frustración es vivida como un trauma y una desaprobación por parte de sus padres; por lo tanto, busca alguna manera de relacionarse con las 


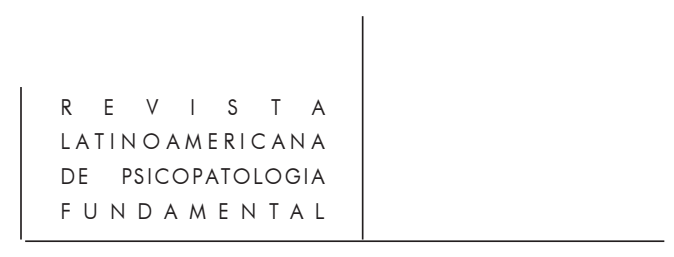

personas significativas de la realidad a cierta distancia óptima, para no sentirse ansioso. Las supersticiones son defensas narcisistas que protegen al niño de su propia rabia al sentirse imposibilitado para enfrentar el mundo externo en ciertas circunstancias, además lo defienden de sentirse indigno. Es decir, cuando la madre no contribuyó al desarrollo de un grado de frustración óptima, y por el contrario intentó satisfacer todas las demandas, el sentimiento mágico omnipotente del niño predomina y se manifiesta en defensas regresivas que pueden observarse a través de las supersticiones religiosas.

Por lo tanto, las identificaciones en los procesos psicóticos supersticiosos infantiles (Dupont, 1988) tienen las siguientes funciones: 1) Se generan de una catástrofe del desarrollo infantil temprano, como instrumentos patológicos del proceso de recuperación; 2) Tienden a sustituir la función de juicio de realidad y a constituirse en un reducto narcisista y omnipotente que preserva la autoestima; 3 ) Tienden a adquirir autonomía, escindiéndose del resto de la personalidad; 4) Dentro del concepto de si mismo, invaden áreas del pensamiento y aparatos perceptuales; 5) Son producto de la reorganización de los fragmentos proyectivos de objetos como sustento permanente de la identificación proyectiva; 6) Imprimen dominio sobre el resto de la personalidad mediante ecuaciones morales inflexibles, su violación despierta dolor físico o moral, culpa o ansiedad. Su obediencia promete bondad, amor y autoestima; 7) Su núcleo organizador aparece como un derivado escindido de un superyo primitivo, punitivo y persecutor; 8) Adaptativamente persiguen la tolerancia a la cercanía y la convivencia con el objeto temido. También permiten la realización de tareas originalmente rechazadas o indeseables.

Agregaríamos la última función de acuerdo a este trabajo:

Las supersticiones son una negociación en las que el niño intercambia vivir con los espíritus, las cuales son las representaciones de sus objetos parentales internalizados, y a pesar de que lo atemoricen; lo acompañan para continuar en contacto con la realidad, y aunque este contacto sea deficiente, no existe una ruptura total.

En el quinto año de tratamiento Lupita comienza a reconocer ciertas situaciones que la tranquilizan y la hacen sentir placer, como su amistad con una vecina y con una compañera de la escuela; también le gusta pintar cerámica con temas de la naturaleza y pensar en Dios que es bueno y protector, pero sobre todo disfruta sus clases escolares. Entonces se le muestra cómo goza y se tranquiliza con la psicoterapia, ante lo que Lupita responde retorciendo todo el cuerpo como señal de angustia ante la cercanía afectiva con la analista. Además comenta que en las sesiones platica cosas que ya había pensado, pero que no había hablado con nadie, y al platicarlas con la analista siente que ella le roba su mente. De esta manera, ante la cercanía afectiva expresa su temor a fundirse con el objeto. Luego pregunta si la 


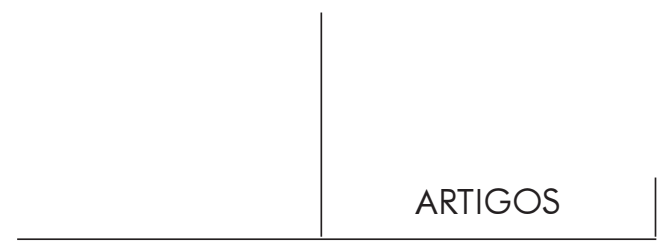

analista no es una bruja, es decir, pregunta si no está disfrazada de la abuela-maga, y de esta forma al mismo tiempo la llama a la sesión para tranquilizarse y aceptar que si le gusta mucho ir a su sesión, con lo que comienza a aceptar la liga afectiva positiva en la transferencia, así como un nuevo camino a la identificación estable, disminuyendo el pavor de fundirse con su abuela y morir en la simbiosis con ella.

Después de un tiempo, llega nuevamente la celebración del día de muertos, y Lupita lleva a su sesión como cada año una ofrenda, pero en esta ocasión no es una calavera de chocolate, sino que ahora es una bruja de chocolate con flores de colores que adornan su cabello y que está batiendo una cazuela. Esta novedosa ofrenda, representación de un ser vivo, es una figura femenina que tiene partes buenas simbolizadas en las flores y en la cazuela que contiene alimento. Además Lupita al entregar este regalo a la analista le pide que lea la leyenda que tiene escrita la caja en la que viene el dulce, y se lee la frase "embrujada por tu amor"; este mensaje habla de la nueva capacidad de Lupita para poder externar un afecto positivo a una persona, de tal manera que Lupita expresa su progreso para relacionarse y logra una negociación con los espíritus que le permite intercambiar la relación temerosa con las ánimas y muertos por relaciones de objeto más humanas y más reales que la tranquilizan.

Para concluir, el niño psicótico supersticioso se recubre con una frazada (Winnicott, 1990) que representa a la madre y se disfraza con ella para protegerse de la realidad que no sabe como enfrentar, actuando como si fueran las ánimas o espíritus de la madre y/o padre-magos, y con estos disfraces se protege de la desintegración. Es la negociación con estos objetos supersticiosos y con los espíritus el niño se protege, pero también con los que juega para estar acompañado por ellos y continuar funcionando en algunas areas de la realidad. Es así que en el consultorio, para los niños psicóticos supersticiosos, las ánimas, los muertos, los demonios y dioses, son sus juguetes con los que negocian su desintegrado mundo interno y el de sus padres. Durante el tratamiento el niño psicótico supersticioso intenta hacer una transacción con estos objetos supersticiosos por otros más reales e integrados, que a través del juego de la transferencia-contratransferencia se le devuelve al niño, a largo plazo, un mundo interno más integrado y un mundo externo más real y más completo.

\section{Referências bibliográficas}

Dupont, M. Psicoterapia de la psicosis en la adolescencia. México: Paidós, 1988.

Fenichel, O. Teoría psicoanalítica de las neurosis. México: Paidós, 1986.

Freud, A. Normalidad y patología en la niñez. Buenos Aires: Paidós, 1989.

Freud, S. (1905). Tres ensayos sobre una teoría sexual. Obras Completas. Madrid: Biblioteca Nueva, 1980. v. II.

GonZÁLEZ, J. Interacción grupal. México: Planeta, 1992. 
MahLer. M. Psicosis infantiles y otros trabajos. Buenos Aires: Paidós, 1990.

PANKow, G. Estructuración familiar y psicosis. Buenos Aires: Paidós, 1979.

RecA, T. Psicoterapia de la psicosis en la adolescencia. Buenos Aires: Paidós, 1979.

Rонеiм, G. Magia y esquizofrenia. Madrid: Paidós, 1982.

Sperling, M. Psicoterapia del niño neurótico y psicótico. Buenos Aires: Hormé, 1980.

WinnicotT, D. W. Realidad y juego. Buenos Aires: Gedisa, 1990.

\section{Resumos}

O menino psicótico supersticioso luta contra suas identificações consistentes, e as superstições se transformam em defesas sem êxito e disfarces de identificações pelo risco de morte psíquica ante regressões psicóticas simbióticas. Lupita, de 10 anos de idade, afirma que às vezes é possuída por maus espíritos, já que, como um corpo sem alma, toma a voz de outro para sobreviver e, assim, através de suas superstições tenta em vão obter uma alma própria.

Palavras-chave: Psicanálise, processos psicóticos, identificações

L'enfant psychotique superstitieux lutte contre ses identifications consistantes. Les superstitions deviennent des défenses sans succès ainsi que des déguisements d'identifications à cause du risque de mort psychique face aux régressions psychotiques symbiotiques. Lupita, âgée de dix ans, assure quelques fois qu'elle est possédée par les mauvais esprits. Etant donné qu'elle est un corps qui manque d'âme, elle prend la voix d'un autre pour survivre. C'est ainsi qu'elle essaye, d'une manière manquée, par l'intermédiaire des superstitions d'avoir une âme à elle.

Mots clés: Psychanalyse, processus psychotiques, identifications

A superstitious psychotic child struggles against his or her solid identifications, and superstitions become unsuccessful defenses and disguises of identification, in view of the danger of psychic death in the presence of symbiotic psychotic regressions. Lupita, 10 years old, says she is possessed by evil spirits, like a body without a soul. She takes on the voices of others in order to survive and, through her superstitions, she attempts in vain to own a soul.

Key words: Psychoanalysis, processes psychotic, identifications

Versão inicial recebida em dezembro de 2000

Versão revisada recebida em agosto de 2001 